ORNL/TM-2011/485
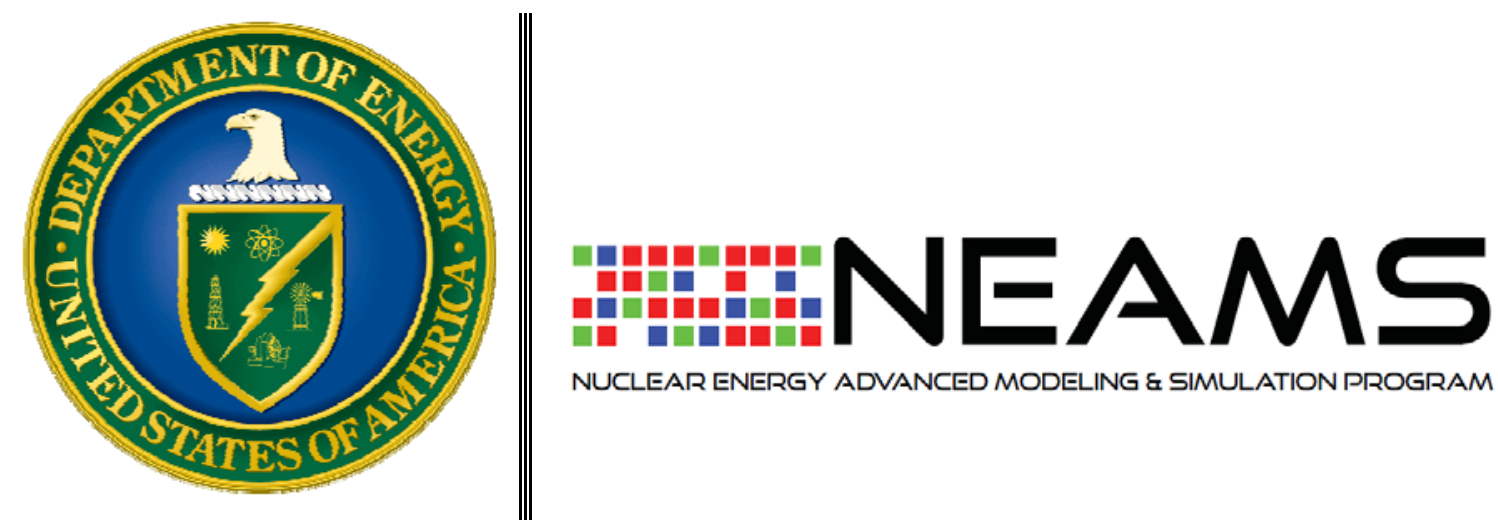

\title{
A Roadmap for NEAMS Capability Transfer
}

Workshop Report

4-5 April 2011

Version 1.1 (2 November 2011)

David E. Bernholdt

Oak Ridge National Laboratory 


\title{
DOCUMENT AVAILABILITY
}

Reports produced after January 1, 1996, are generally available free via the U.S. Department of Energy (DOE) Information Bridge.

Web site http://www.osti.gov/bridge

Reports produced before January 1, 1996, may be purchased by members of the public from the following source.

\author{
National Technical Information Service \\ 5285 Port Royal Road \\ Springfield, VA 22161 \\ Telephone 703-605-6000 (1-800-553-6847) \\ TDD 703-487-4639 \\ Fax 703-605-6900 \\ E-mail info@ntis.gov \\ Web site http://www.ntis.gov/support/ordernowabout.htm
}

Reports are available to DOE employees, DOE contractors, Energy Technology Data Exchange (ETDE) representatives, and International Nuclear Information System (INIS) representatives from the following source.

Office of Scientific and Technical Information

P.O. Box 62

Oak Ridge, TN 37831

Telephone 865-576-8401

Fax 865-576-5728

E-mail reports@osti.gov

Web site http://www.osti.gov/contact.html

This report was prepared as an account of work sponsored by an agency of the United States Government. Neither the United States Government nor any agency thereof, nor any of their employees, makes any warranty, express or implied, or assumes any legal liability or responsibility for the accuracy, completeness, or usefulness of any information, apparatus, product, or process disclosed, or represents that its use would not infringe privately owned rights. Reference herein to any specific commercial product, process, or service by trade name, trademark, manufacturer, or otherwise, does not necessarily constitute or imply its endorsement, recommendation, or favoring by the United States Government or any agency thereof. The views and opinions of authors expressed herein do not necessarily state or reflect those of the United States Government or any agency thereof. 


\begin{tabular}{|l|l|l|}
\multicolumn{2}{|c}{ Version History } \\
\hline Version & Date & Changes \\
\hline Initial draft & $2011-06-21$ & \\
\hline 1.0 & $2011-07-07$ & Incorporate participant and reviewer comments. \\
\hline 1.1 & $2011-11-02$ & $\begin{array}{l}\text { Incorporate additional participant comments. Format as ORNL Technical } \\
\text { Report. }\end{array}$ \\
\hline
\end{tabular}




\section{Table of Contents}

1 Executive Summary___ 5

2 Background ___ 7

3 Summary of the NEAMS Capability Transfer Roadmapping Workshop __ 9

3.1 Introduction to the NEAMS Program__ 9

3.2 User Outreach and Technology Transfer in Other Modeling \& Simulation Programs _ 9

3.2.1 Advanced Simulation and Computing (ASC), Gil Weigand, ORNL ___ 9

3.2.2 Standardized Computer Analyses for Licensing Evaluation (SCALE), Brad Rearden, ORNL _ _ 10

3.2.3 Consortium for Advanced Simulation of Light Water Reactors (CASL), Jess Gehin, ORNL _ _ 10

3.3 Discussions _ 11

3.3.1 Fuels/Reactors Breakout____ 11

3.3.2 Safeguards \& Separations/Waste Breakout __ 12

3.3.3 General Discussions ___ 13

4 Recommendations and Proposed Roadmap

4.1 Recommendations for NEAMS Capability Transfer Activities _ 15

4.2 Recommended Roles and Responsibilities __ 17

4.3 Roadmap to Rich, Robust Capability Transfer in NEAMS _ 18

Appendix A Workshop Agenda __ 20

Appendix B Workshop Attendees ___ 22 


\section{Executive Summary}

The vision of the Nuclear Energy Advanced Modeling and Simulation (NEAMS) program is to bring truly predictive modeling and simulation $(M \& S)$ capabilities to the nuclear engineering community in order to enable a new approach to the design and analysis of nuclear energy systems. From its inception, the NEAMS program has always envisioned a broad user base for its software and scientific products, including researchers within the DOE complex, nuclear industry technology developers and vendors, and operators. However activities to date have focused almost exclusively on interactions with NEAMS sponsors, who are also near-term users of NEAMS technologies. The task of the NEAMS Capability Transfer (CT) program element for FY2011 is to develop a comprehensive plan to support the program's needs for user outreach and technology transfer.

In order to obtain community input to this plan, a "NEAMS Capability Transfer Roadmapping Workshop" was held 4-5 April 2011 in Chattanooga, TN, and is summarized in this report. The 30 workshop participants represented the NEAMS program, the DOE and industrial user communities, and several outside programs. The workshop included a series of presentations providing an overview of the NEAMS program and presentations on the user outreach and technology transfer experiences of

- The Advanced Simulation and Computing (ASC) program,

- The Standardized Computer Analysis for Licensing Evaluation (SCALE) project, and

- The Consortium for Advanced Simulation of Light Water Reactors (CASL),

followed by discussion sessions.

Based on the workshop and other discussions throughout the year, we make a number of recommendations of key areas for the NEAMS program to develop the user outreach and technology transfer activities:

- Engage not only DOE, but also industrial users sooner and more often.

- Engage with the Nuclear Regulatory Commission to facilitate their understanding and acceptance of NEAMS approach to predictive M\&S.

- Place requirements gathering from prospective users on a more formal footing, updating requirements on a regular basis and incorporate them into planning and execution of the project in a traceable fashion.

- Seek out the best available data for validation purposes, and work with experimental programs to design and carry out new experiments that satisfy the need for data suitable for validation of highfidelity M\&S codes.

- Develop and implement program-wide plans and policies for export control, licensing, and distribution of NEAMS software products.

- Establish a program of sponsored alpha testing by experienced users in order to obtain feedback on NEAMS codes.

- Provide technical support for NEAMS software products.

- Develop and deliver documentation, tutorial materials, and live training classes.

- Be prepared to support outside users who wish to contribute to the codes. 
Nearly all of these activities involve collaboration between staff of the Capability Transfer program element and the IPSC teams, and sometimes other program elements as well. Leadership of these activities naturally rests with CT in some cases, and the IPSCs in others. 


\section{Background}

The vision of the NEAMS program is to bring truly predictive modeling and simulation (M\&S) capabilities to the nuclear engineering community in order to enable a new approach to the design and analysis of nuclear systems ${ }^{1}$. This vision leverages advances in high-performance computing, as well as computational science and engineering to change the relationship between experiment and simulation - as has already happened in many other fields of science and engineering. The goal is not to eliminate experiments, but rather to optimize how the measurements are used to gain scientific insight or solve problems of interest. . In order to significantly influence the trajectory of nuclear M\&S capabilities, NEAMS emphasizes increasing accuracy and fidelity, and broadening the range of applicability of methods. Uncertainty quantification is also considered extremely important to predictive capabilities. At the same time, there is an emphasis on ease of use and integration into current design and safety analysis processes, as well as ease of maintenance and future development of the software.

NEAMS contributes to all four of the Office of Nuclear Energy's R\&D “Imperatives” with a number of different milestones:

- Sustain the current fleet

o 2014 - State of the art predictive reactor core analysis capability

o 2019 - Performance models developed to enable applications for reactor life extensions

o 2019 - Fully-coupled safety analysis tools validated and issued to industry

- Affordable new reactors

o 2015 - Complete 3-D high fidelity reactor core simulator

o 2015 - Demonstrate advanced modeling and simulation tool for SMR plant design, performance, and safety validation

- Sustainable fuel cycle

o 2015 - Development of a framework for advanced computational models for disposal system performance

- $\quad$ Reduced proliferation risk

o 2020 - Test fully integrated advanced material measurement and information analysis systems

The NEAMS program is organized into four Integrated Performance and Safety Code activities (IPSCs) and four Crosscutting Methods and Tools activities (CMTs). The four IPSCs (Reactors, Fuels, Safeguards \& Separations, and Waste) are developing initial versions of their codes primarily by building on existing software packages, with targeted refinements. New and improved methods and models will be implemented progressively, over time. Although none of the programs are organized in exactly the same way, the NEAMS IPSC teams coordinate their work with other Office of Nuclear Energy (NE) R\&D

1 NEAMS and the CASL Energy Innovation Hub are managed by the Advanced Modeling and Simulation Office (AMSO, NE-71). This office is the primary, but not exclusive, home for modeling and simulation within the Office of Nuclear Energy. AMSO's focus is on detailed, high-fidelity M\&S. Other M\&S activities generally serve more specific programmatic needs. For example, the Fuel Cycle R\&D Program's Fuel Cycle Simulator is a tool to facilitate planning and policy decisions related to different fuel cycle choices, looking across an entire fleet of reactors and related facilities. 
programs and with the nuclear Energy Innovation Hub. The four CMTs (Fundamental Methods and Models (FMM), Verification, Validation and Uncertainty Quantification (VU), Enabling Computational Technologies (ECT), and Capability Transfer (CT)) are intended to provide capabilities required by more than one IPSC, facilitate the interoperability of the IPSCs, provide consolidated program interfaces to various stakeholders, and support user outreach and technology transfer.

From its inception, the NEAMS program has always envisioned a broad user base for its software and scientific products, including researchers within the DOE complex, nuclear industry technology developers and vendors, and operators. However, apart from interactions with NEAMS sponsors, who are near-term users of NEAMS technologies, there has thus far been no concerted effort within the program towards user outreach and technology transfer. Initially, the Capability Transfer element of the program was focused on technological solutions to facilitate interoperability across the IPSCs and increase usability of the M\&S tools. User interactions have been primarily the province of the IPSC teams, and have not been a primary focus. As work progressed, it became clear that some changes were needed. During FY2010 and FY2011, CT's technology development activities were realigned to become part of the ECT program element. CT's sole task in FY2011 was to "reinvent" the program element to directly support the program's needs for user outreach and technology transfer. As the year progressed, we conducted numerous discussions with NEAMS participants, program managers, and others working in the nuclear area. These discussions were capped by a workshop bringing together NEAMS participants and program managers, and representatives of the targeted DOE complex and industry user communities. This report documents that workshop, and synthesizes the various inputs received into a recommended roadmap for the creation of a rich, comprehensive Capability Transfer activity for the NEAMS program. 


\section{Summary of the NEAMS Capability Transfer Roadmapping Workshop}

The NEAMS Capability Transfer Roadmapping Workshop was held 4-5 April 2011 at the Chattanooga Convention Center, Chattanooga, Tennessee, organized by David Bernholdt (NEAMS CT Lead), Jim Peltz (DOE Program Manager for NEAMS Crosscutting Methods and Technologies), and Keith Bradley (National Technical Director for NEAMS). Thirty people, representing the NEAMS program, the DOE and industrial user communities, as well as several outside programs, attended the two-day event (see Appendix B). The summary below is organized along the lines of the workshop agenda (see Appendix A). Presentations and breakout discussion summaries are available online, at http://www.ne.anl.gov/NEAMS/meetings/CTroadmap.

\subsection{Introduction to the NEAMS Program}

The workshop began with a series of presentations introducing the NEAMS program.

- Overview of the NEAMS Program (Jim Peltz, DOE)

- $\quad$ Fuels IPSC (Steve Hayes, INL)

- $\quad$ Reactors IPSC (David Pointer, ANL)

- Safeguards and Separations IPSC (David DePaoli, ORNL)

- Waste IPSC (Carter Edwards, SNL)

- Fundamental Methods and Models (Xin Sun, PNNL)

Because the NEAMS community is already quite familiar with these topics, and the presentations are available online, we will not attempt to summarize them here.

\subsection{User Outreach and Technology Transfer in Other Modeling \& Simulation Programs}

In the second part of the workshop, we heard presentations from representatives of three related largescale M\&S programs with similar goals, emphasizing their approach to user outreach and technology transfer.

\subsubsection{Advanced Simulation and Computing (ASC), Gil Weigand, ORNL}

The ASC (previously Accelerated Strategic Computing Initiative (ASCI)) program is a large scale, long term effort to develop robust, predictive M\&S capabilities for the US nuclear weapons program. Conceptually, it is one of the inspirations for the NEAMS program. There are many lessons to be learned from the ASC program, but two in particular stand out in this context.

One lesson has to do with the importance of using M\&S codes to solve real, challenging problems. "Real" in this context means that the design of test cases was driven by the needs of the analysis down in the trenches rather than things that would sound good to sponsors. "Challenging" means things that are not possible to simulate (accurately) when the problem is posed. The experience was that solving problems the analysts considered important was very powerful in helping to convert M\&S skeptics into not just believers, but even supporters - thus creating a bottom-up "pull” for the sponsors to fund even 
more M\&S. These challenge problems were also sometimes used to motivate code teams, by making continued funding contingent on being able to produce accurate answers.

Another important lesson had to do with the relationship between simulation and experiment. Historically, the weapons program had been entirely experiment-driven (on both components and integrated systems). Of course ASC was motivated in large part by the Comprehensive Test Ban Treaty, which took one class of experiments off the table. However there was a great deal of anxiety, both about the ability of M\&S to provide the required predictive capabilities, and, simultaneously, about the idea that M\&S might end up replacing the entire experimental program. In the course of time, as ASC's M\&S capabilities matured, the relationship between the modelers and the experimentalists changed. As the quality of the simulations increased, they could be used in an exploratory fashion, to help focus and drive (expensive and potentially dangerous) experiments so that they could provide more useful results, and rely less on trial-and-error. In the long run, simulation ended up complementing rather than replacing experiments, and in fact, the total spending on experiments increased rather than decreased as the ASC program matured.

\subsubsection{Standardized Computer Analyses for Licensing Evaluation (SCALE), Brad Rearden, ORNL}

The Standardized Computer Analyses for Licensing Evaluation (SCALE) package provides simulation capabilities for criticality safety, radiation shielding, cross-section processing, reactor physics, and spent fuel and high-level waste characterization with sensitivity and uncertainty analysis. Development started in 1976 for the Nuclear Regulatory Commission and now has more than 3000 users in 40 countries. The SCALE team currently receives funding from several agencies for multiple distinct projects, totaling approximately \$10M annually. As a 0D999 export-controlled package, it is distributed in the US through the Radiation Safety Information Computational Center (RSICC) and internationally through the Organization for Economic Cooperation and Development/Nuclear Energy Agency (OECD/NEA) Data Bank. The SCALE team places a strong emphasis on quality assurance (QA) of their software, spending roughly $\$ 800 \mathrm{k}$ annually on software maintenance. The SCALE QA plan was developed for compliance with DOE O 414.1c, and is currently being updated to satisfy NQA-1 and ISO 9001. The SCALE team carries out a variety of user outreach activities. Training courses take place at ORNL on a regular basis: Four week-long sessions on different topics, presented twice a year, with 10-20 participants each week. They also provide training courses at other sites (DOE labs, OECD, IAEA, and user facilities) 2-4 weeks per year (estimated at $\$ 200 \mathrm{k}$ annually in attendee-paid costs). They also present workshops free of charge at various conferences around the world. Other resources include written "primers" which serve as guides to get users started on specific topics, the SCALE web site, a Facebook page, a newsletter (10-12 pages, published twice per year), and "user notebooks" (frequently-asked question files). Beyond the basic support provided by the RSICC code distribution center, the SCALE team provides email support, fielding hundreds of issues per year. SCALE's approach to QA and user outreach can provide a valuable model for NEAMS to emulate, while recognizing that, it has had a great deal of time to mature.

\subsubsection{Consortium for Advanced Simulation of Light Water Reactors (CASL), Jess Gehin, ORNL}

CASL is first of the three Energy Innovation Hubs launched so far by the DOE. It is funded for a five year period, with up to two five-year renewals possible. The originally expected funding level was $\$ 25 \mathrm{M} / \mathrm{yr}$, but in fact, the first two years of funding have totaled about $\$ 38 \mathrm{M}$ (rather than $\$ 50 \mathrm{M}$ ). The core CASL team includes ten partner institutions, led by ORNL, with an additional twelve institutions contributing. The driving idea behind CASL is to develop a "virtual reactor" capable of predictive modeling of currently operating light water reactors. CASL is organized around five focus areas, including Models and Numerical Methods (MNM), Materials and Performance Optimization (MPO), Virtual Reactor Integration (VRI), Validation and Uncertainty Quantification (VUQ), and Advanced 
Modeling Applications (AMA). Technology transfer is "baked in" to the design of CASL, through the direct participation of a vendor (Westinghouse), a utility (TVA), and an industry R\&D organization (EPRI) in the project. CASL's Industry Council provides even broader connections. Technology transfer in CASL is carried out primarily through the AMA focus area. They plan to use a "test stand" concept to provide early deployment of virtual reactor capabilities to actual engineering/design environments of their industry partners (Westinghouse, TVA, and EPRI). These test stands will address real industry problems while providing feedback to CASL development teams. Industry-provided data (from Westinghouse test facilities and operating TVA reactors) will facilitate validation of CASL models. Once proven through AMA's test stand activities, CASL-developed capabilities will be made available for broader use by their industry partners. Approximately \$2.9M of CASL's annual budget is devoted to the AMA focus area.

\subsection{Discussions}

There were also free-form discussion sessions designed to elicit input from the participants as to topics and strategies of interest to the NEAMS program.

\subsubsection{Fuels/Reactors Breakout}

For the Fuels IPSC, fuel performance and cladding issues (e.g., hydride limits) were considered the most important contributions NEAMS could make. For Reactors, a number of areas were of interest, including thermal-hydraulics capable of accurately modeling fuel assembly grids, providing detailed power distributions, seismic modeling, and coupled neutronics/CFD/heat transfer for transients. Generally, there is strong interest in tools that can improve safety margins and operational flexibility.

The group felt that the incorporation of more physics into the modeling could be valuable in order to avoid having to justify assumptions and approximations, and were willing to accept longer run times for better accuracy. However the codes also need to be responsive to user needs, including the ability to choose (perhaps indirectly) the time and resources devoted to the simulation. Similarly, codes should support accurate representation of the geometries of real systems in order to avoid approximations and the associated questions. Setup time for simulations was described as a concern. There was a general feeling that it was not necessary to have complete, fully integrated packages in order to have value, though it was noted that for small modular reactors (SMRs) in particular, integration becomes more important.

In response to the presentation on the Fundamental Methods and Models (FMM) program element, the group noted that such activities were definitely required as part of an R\&D program in order to advance theory and validate physics models. Also, fuel cladding needs that level of detail directly, and vendors may be interested in direct use of such models.

The group identified a number of gaps in the current NEAMS R\&D portfolio that they felt would be worthy of additional consideration. Structural analysis, seismic modeling, and concrete structures were pointed out, as was tools for economic analysis.

Historically, issues considered when bringing a new code into an organization include training and the knowledge necessary to run the code (often solved by hiring someone with experience with it), computational resources on which to run it, and the qualification, verification, and validation (to NQA-1 requirements) of the code. Flexibility of the code and the ability to use selected portions of its capabilities are also a consideration. Participants felt that the most likely role for NEAMS codes would initially be as a reference tool for the verification of production tools. Further penetration into production workflows might happen over time, in an evolutionary fashion. Vendors may well want to adapt or modify the codes, perhaps using only selected modules or capabilities, while utilities are more likely to use them as distributed. Software lifecycle also needs to be taken into account. While in many cases, stability of codes will be important for licensing reasons, there is also a need to update codes regularly, particularly 
for bug fixes. Well-defined release schedules and backward compatibility of releases would be important in this context. Codes that have long development times should consider intermediate releases with useful subsets of the complete functionality. Users would expect the software to follow a well-defined and documented quality assurance plan, which should also be available to users.

Code verification is considered to be the responsibility of the software developers, but must be reproducible and carefully documented and made accessible to users. Validation is a shared responsibility. The NRC places responsibility for validation on the user, however this is also part of developing a useful, predictive code. Validation test cases and data were noted as a potential challenge for both developers and users because of the proprietary nature of much of the data. Solutions proposed involved collaboration between developers and users to allow developers access to high-quality proprietary user data for validation purposes, while simultaneously developing comparable test cases with more generic non-proprietary data that can be distributed generally with the code for the broader user base. It was also noted that the terms "uncertainty quantification" and "verification and validation" have somewhat different meanings in different communities within the field, and that it would be useful to try to clarify those definitions prior to undertaking such collaborations.

Most organizations have their own data management systems, and would expect to integrate new codes with such systems; however this is viewed as relatively straightforward because it is done routinely.

In terms of what NEAMS can do to facilitate the adoption of their codes by users, a number of suggestions were made:

- "Must have" items:

o User documentation, including models/methods provided in the code;

o Detailed examples and tutorial materials, suitable for self-study;

o Training classes; and

o Formal technical support via phone and/or email.

- Additional “nice to have” items:

o Developer documentation;

o Informal access to developers;

o Community-based support (i.e. user mailing lists); and

o In some cases, access to high-end computing resources.

\subsubsection{Safeguards \& Separations/Waste Breakout}

In this area, there are number of computational tools used throughout the industry, plus additional (generally commercial or proprietary) tools. SCALE, ORIGEN (which is part of the SCALE package), and AutoCAD were cited as universal. Most organizations have document/data management systems layered on top of their tools to facilitate capture and exchange of information. Shaw Group representatives mentioned the use of Intergraph's suite of engineering tools as providing a common data model. Energy Solutions also does stochastic process modeling with tools such as Aspen Custom Modeler and gPROMS. AREVA uses a largely proprietary suite of tools.

One concrete example of where NEAMS could contribute to the Safeguards \& Separations area was discussed. While industry is already (mostly) able to predict the constitution of off-gasses, they do not currently have the capability to model how to separately capture different off-gasses (i.e., iodine vs. tritium). Industry representatives pointed out that there is data available from separations plants, and that vendors could probably provide some generic plant designs which would be useful for validation while 
avoiding proprietary issues. There was also a discussion of voloxidation. This is often cited as an example of new M\&S capabilities being developed by NEAMS. Industry representatives pointed out that this may not be the best example to present to an industry audience because it is not a process in current use, and industry has many practical concerns about it. On the other hand, it serves as an example of how NEAMS can provide tools that would facilitate exploration beyond the current state of practice.

It was observed that the user communities have somewhat different needs from a program like NEAMS. Researchers within the DOE complex generally have very broad, long time-scale research programs they are interested, for example, in tools to investigate the system level for safeguards instruments. Industry, on the other hand, has a much more focused set of needs, and already has tools that address (most of) those needs. They are most interested in tools that can easily "drop in" to their existing M\&S tools and workflows to provide better predictive capability, better performance, etc. The software needs to be extensible, with flexible licensing provisions. They are generally using workstation-level compute resources, and like to work with a graphic user interface (there is a perception in the community that NEAMS is focused exclusively on high-end solutions that require HPC resources). A solid set of examples and trainings are a must.

Lower length-scale modeling was viewed by this group as important, but not immediately or directly useful to them. There is a perception in the community that NEAMS is driven by the high-fidelity lower length-scale M\&S.

The suggestion was made to look at professional societies (e.g., American Nuclear Society, ASME, Institute of Electrical and Electronics Engineers) both as venues for outreach, and possibly as homes for M\&S-related "standards" bodies, should they be needed.

\subsubsection{General Discussions}

Following the breakout discussions, the whole group reconvened to hear summaries of the breakouts and continue and expand on prior discussions. Varieties of topics came up, or were reinforced during this session.

Paul Murray (AREVA) observed that even with ample data from European operations, they have estimated that the qualification of high-level waste glass for use in US repositories will require 15 years and cost $\$ 250 \mathrm{M}$. He suggested this as an opportunity for NEAMS to find ways to make this process faster and cheaper. Elsewhere, John Vienna (PNNL) has said it will take approximately 10 years to qualify glasses for each of Hanford's seven different waste types.

More generally, industry has a broad base of M\&S tools that meet their needs and have been used in many NRC-licensed facilities and activities. NEAMS software is unlikely to replace such tools, but can be useful in other contexts, such as design, exploration, and reference. Where NEAMS can have the most impact is in areas for which they do not currently have the needed M\&S capabilities (several examples have already been cited), or where substantial improvements of M\&S capabilities are needed (e.g., design of small modular reactors without pumps requires better thermal-hydraulics-neutronics modeling than is currently available). NEAMS products may also be useful additions to the more exploratory phases of industrial development activities.

Conversely, Keith Bradley challenged the industrial representatives to think further ahead about their M\&S needs, in order to better align with NEAMS development timelines and topical focus areas (i.e., fast reactors in addition to LWRs).

An important difference was noted in that NEAMS is developing tool sets rather than solving specific end-to-end problems, like CASL. This makes for a somewhat different relationship with users.

There were discussions of the relationship of NEAMS to the Nuclear Regulatory Commission (NRC). It was noted that while regulators in other countries typically require continual innovation and improvement 
in designs and the supporting evidence, the NRC tends to prefer stability. Given the innovative nature of NEAMS's goal of developing truly predictive M\&S capabilities, industry representatives advised that NEAMS should engage with the NRC "early and often" as we are developing our tools rather than simply presenting them with completed products at the end of development.

Related to this, there were discussions of a variety of topics related to $V \& V$ and software quality assurance. The point was reiterated that V\&V means different things to different organizations, and it would be useful for NEAMS IPSCs and the VU CMT to engage with industry representatives to harmonize language, expectations, and approaches. There was also discussion of making stronger connections to experimentalists, both in the DOE complex and in industry, in order to help educate experimentalists about the kinds of details that need to be considered in producing data that is useful for validation of high-fidelity M\&S. Examples were cited from past experience of the geometries of pinbundle spacer grids not being known in sufficient detail, or cases where real spacers did not exactly match the CAD drawings that were used in simulations.

There was also general discussion of the fact that industry has a great deal of data from test loops and operational systems that could be quite valuable for validation of NEAMS M\&S codes. Because most of this data is considered proprietary, there are significant challenges in reconciling the desire for the best possible experimental data with the desire to have at least some validation evidence that can be publically distributed with the codes. Several strategies were discussed. First of all, there may be data from older systems that might be considered less proprietary, and therefore more open to distribution. Second, many problems can be "genericized" (e.g., a proprietary contactor design replaced with a generic one) to reduce or eliminate proprietary content. These approaches might be combined with specific collaborations between NEAMS IPSC teams and companies to tackle the more specific proprietary versions of the problems, which would give the companies access to tools validated on their specific problems, and give NEAMS additional confidence in their codes in general. 


\section{Recommendations and Proposed Roadmap}

We begin by making recommendations for activities oriented towards user outreach and technology transfer which we believe that the NEAMS program needs to consider regardless of the organization of the program. Then, in the context of the current program organization, which includes a separate Capability Transfer (CT) program element meant to support the IPSCs, we revisit those activities and make recommendations for roles the CT team, the IPSC teams, and others in NEAMS should play in implementing each activity. Finally, we lay out a roadmap for how the recommended activities might be developed over time.

It is important to note the structure of this section. We believe there should be little debate over the list of issues that NEAMS must address if it is to successfully reach out to users. The division of labor is more open to discussion amongst program participants and management, while following the approach and timeline of the roadmap is primarily a managerial matter.

\subsection{Recommendations for NEAMS Capability Transfer Activities}

NEAMS is a large program with a broad spectrum of activities aimed at producing a variety of M\&S tools. The primary applications of these tools are expected to be by users outside of the NEAMS program. The initial target users for most NEAMS products are researchers in the NE campaigns, which have also been the primary sponsors of NEAMS R\&D2. The commercial nuclear industry (vendors and utilities) have been discussed as second and third groups to target, recognizing that there are differences in the needs and interests of vendors and utilities. To date, NEAMS user interactions have been focused on the NE campaigns, and have primarily revolved around incorporating user requirements into the NEAMS R\&D program and software development. As NEAMS begins to deliver M\&S software capabilities, there is a need to extend both the depth and breadth of the program's interactions with users.

In terms of breadth, the obvious need is to extend interactions to encompass the industrial user community. Even though it may be some time before NEAMS software tools reach the levels of predictive maturity and usability to be "interesting" to industrial users, it is important that the conversation between NEAMS and this community begin with requirements gathering and the development of appropriate $R \& D$ plans to ensure that the needs of the community are addressed, and strategies can be developed to facilitate adoption of NEAMS products within this community. A second community that NEAMS needs to engage is the Nuclear Regulatory Commission (NRC). While the tools NEAMS is developing are not expected to be used directly in license applications, the predictive approach NEAMS is pioneering is sufficiently different from current practice that industrial representatives at the workshop specifically recommended beginning discussions with the NRC as early as possible in order to facilitate understanding and acceptance of NEAMS's approach. However it is not clear what is the best way to go about this, so the initial action item in this area is to make the connections between NEAMS and the NRC and determine what the scope of this activity should be. Once this relationship is better understood, it will be necessary to evaluate whether there is a further role for CT staff to play in on-going interactions with the NRC.

\footnotetext{
${ }^{2}$ Through FY2011, the NEAMS program has been directly funded by several NE campaigns. Beginning in FY2012, the program will have an independent funding line, however AMSO hopes to attract additional support from various NE campaigns to enhance and extend relevant M\&S capabilities beyond the reach of the NEAMS budget alone.
} 
In terms of depth, NEAMS has a long way to go. In this early stage of the NEAMS program, the primary interaction with users has been to incorporate their needs and requirements into NEAMS R\&D plans and software development activities, often in a relatively ad hoc fashion. Because the development of truly predictive M\&S capabilities is a long-term effort, it would be appropriate to place requirements gathering and tracking activities on a somewhat more formal footing. Having each IPSC maintain (and periodically update) a publicly available requirements document would give (prospective) customers better insight into what the developers are working on. Being able to trace development plans back to a well-defined list of requirements would help the IPSCs plan, prioritize, and justify their development activities. Traceability through to the final product can also help the development teams identify key stakeholders to help test new features and capabilities, and target outreach.

Validation is a critical aspect of developing a predictive M\&S capability. There is a wealth of experimental and operational data that has been collected over the years, both in the DOE labs and in industry. The NEAMS program needs to be more proactive in thinking about the validation data it would like to have, what it can make use of, and in seeking it out. There may be both technical and nontechnical challenges to the acquisition and use of validation data. Technically, questions often arise as to whether a given data set contains data in a form and resolution that can be used effectively with the M\&S tools to be validated. Additionally, the experimental system may or may not have been adequately characterized to allow accurate simulation. On the non-technical side, the (industrial) data is often proprietary, and consideration must be given to how to balance the desire to have the best possible validation for the codes NEAMS is developing with the desire to have as many test cases as possible as part of the openly-distributed software package. These issues will take time to address, and there may or may not be uniform strategies for dealing with them, which suggests that they should begin to be addressed well in advance of the actual need. Similarly, the NEAMS program has the opportunity to influence new experiments planned by NE and by industry, and should therefore be thinking ahead to what new data would improve the validation opportunities for the codes being developed, as well as reaching out to the experimental teams to educate them on the particular issues associated with validation of high-fidelity predictive $M \& S$ codes so that new experiments can provide maximum value to the program.

As NEAMS software reaches levels of maturity where it is ready for use beyond the development team, the issue of export control, licensing and distribution of the software arises. At present, NEAMS has no express policy as to either of these issues; however program management has expressed a preference for open source licensing wherever possible, and has suggested the Radiation Safety Information Computational Center (RSICC) for distribution. On the other hand, past experience with at least some of the codes that will play a role in NEAMS is that they have been used as bargaining chips in international exchanges of nuclear data and software, and it is not clear how the choice of license and distribution policies affect such opportunities, and whether they remain a strategic consideration for NE. There is a need to develop programmatic guidance on these issues before individual code teams are forced to make decisions on these questions in order to get their codes into the hands of users. Once these distribution policies have been established, it will be necessary to evaluate whether there is a further role for CT staff to play in the distribution of NEAMS software products.

Testing is also an important consideration, especially for products that are near or ready to release to a wider audience. While there are certainly expectations that the development teams will test extensively, in accord with a strong software quality assurance plan, experience in the software industry suggests that there is only so much that can be accomplished by developers testing and exercising their own codes. There is a clear need for testing by users with a degree of separation from the developers, who need to rely on the documentation delivered with the code, and who don't know (and therefore, know to avoid) the code's quirks. For early-stage testing, knowledgeable and experienced "friendly users" from the target R\&D community are likely to provide the most useful and informative assessments and feedback. Such individuals can formulate scientifically relevant problems to apply the codes to, and as respected 
members of their communities can become useful advocates for the new codes and capabilities within their R\&D communities. Particularly during the initial "alpha" and "beta" testing stages, it is also very important that there be open communication channels between the users and developers so that user feedback can be captured and acted upon to improve the product. It is quite common for early-stage users to be financially supported in order to help insure that users actually take the time to do the testing and provide feedback. Using an unfamiliar tool, even for familiar simulations, will be more time consuming, and often more frustrating, so users will have little motivation to deviate from their usual work flows. Feedback on the product, rather than scientific results from using it, is the appropriate deliverable for early testers.

Once the codes are in the hands of users, they will need some level of support. This includes basic technical support, via phone and email, with appropriate tracking to insure that issues don't fall through the cracks. It also includes thorough documentation, not only of how to use the codes, but also detailed information on the equations being solved and the assumptions being made (details of the implementation would also be useful, but this can raise export control issues). In addition, users want fully documented "worked examples" and tutorial materials to help them learn the products. Mailing lists or online discussion forums can facilitate communications both between users and developers as well as developers among themselves. The latter may allow a degree of community-based self-support. For many, live training classes would also be useful.

Finally, if users are to become developers of the software - either making modifications for their own use, or contributing patches and improvements back to the main stream of development - then a higher level of support is needed. This includes developer documentation, and perhaps access to the development environment the IPSC team is using (e.g., code repository, issues trackers, developer mailing lists). In discussions to date, code development by users does not appear to be of significant interest, however it does need to be kept in mind as the codes and the user base evolves with time because opening up development, especially in a National Laboratory setting, can pose some time-consuming challenges.

\subsection{Recommended Roles and Responsibilities}

We have described a wide range of activities that we believe should be part of an overall Capability Transfer effort within the NEAMS program without giving any indication as to who should be responsible for them. This is in part to emphasize that these are ultimately programmatic issues for which responsibility must be shared across all NEAMS participants and management. However, in practice, when everyone is responsible, no one is responsible. Within the structure of the NEAMS program, it is logical to assign the cross-cutting Capability Transfer (CT) program element overall responsibility for and oversight of all capability transfer activities. However in many of the activities described, the IPSC teams must also take an active role. Our general approach in assigning roles and responsibilities views the CT team as a first line of "defense" for the IPSC teams, helping to smooth out the frequent interruptions and distractions that can often arise when serving a user community, and also as a central hub for activities that are similar or identical across the IPSCs.

In expanding the breadth of the NEAMS user interactions - extending into the nuclear industry, and interacting with the NRC, it is appropriate for the CT program element to take the lead, although strong support from domain experts (from the IPSCs or elsewhere) will be needed, particularly for interactions with industry.

Requirements gathering is a process that the IPSCs need to take primary responsibility for, with the CT program element assisting to help cast as wide a net as possible in the collection process, and to help ensure that the results are appropriately visible to the user community.

Ultimately, it is up to the IPSCs to define and obtain the data they require for validation of their codes. However because all such exchanges will entail similar intellectual property and other "business" 
considerations, it will be useful to the CT team to take on the role of coordinating such exchanges with the goal of developing experience that can be leveraged across multiple IPSCs and data providers.

CT should take the lead in developing recommendations for common, program-wide export control, licensing and distribution policies for NEAMS software products. However the appropriate roles of CT and the IPSCs in actually implementing these policies will depend on their specifics and their definition, and must therefore be deferred until the policies are established.

As mentioned above, a key consideration for software testing is maintaining a degree of separation between the developers and the testers. Therefore, we recommend that CT be responsible for overseeing alpha (and possibly beta) testing activities. Clearly, strong support will be required from the IPSC teams to help identify appropriate testers, ensure that they can get the software working, and, of course, respond to feedback from the testers. However this is also a good opportunity for the CT team to start developing a level of experience and expertise with the software in order to facilitate later support efforts. As such, we recommend that CT appoint a liaison to work closely with the testers and serve as their primary point of contact with the developers while simultaneously working with the code on their own (trying to stay a step ahead of the testers).

Given the development of sufficient expertise in the CT team, CT can take responsibility for providing basic "tier-1" support to users, thus providing some insulation for the developers.

The development of examples, tutorials, and trainings should be a joint effort between the IPSCs and CT. The roles for these activities is not clear cut, but a logical approach would be to place CT in the coordination and oversight role, so that it could work across IPSCs to ensure consistent look and feel and quality. Significant portions of the content should originate with developers, who are the subject matter experts, but the CT team can play a strong role in helping to refine and improve the content and presentation, leveraging their experience with users. Where possible, we recommend that live training events should be conducted jointly by IPSC experts and knowledgeable CT staff.

As users become developers, the IPSC team should take the lead in handling those interactions, with CT as observers.

\subsection{Roadmap to Rich, Robust Capability Transfer in NEAMS}

\begin{tabular}{|l|l|l|l|}
\hline Starting & Frequency & Activity & Roles \\
\hline FY11 & Annual & $\begin{array}{l}\text { Community meeting for progress } \\
\text { updates and requirements gathering }\end{array}$ & $\begin{array}{l}\text { IPSCs: Lead } \\
\text { CT, Others: Observer }\end{array}$ \\
\hline FY12 & One-time & Develop software distribution plan & $\begin{array}{l}\text { CT: Lead } \\
\text { IPSCs, ECT, DOE: Contributor }\end{array}$ \\
\hline FY12* & On-going* & Sponsored alpha testing & $\begin{array}{l}\text { CT: Lead, develop experience for tier-1 } \\
\text { support } \\
\text { IPSCs: Help identifying users, provide } \\
\text { user support }\end{array}$ \\
\hline FY12 & One-time & Develop NRC engagement strategy & $\begin{array}{l}\text { CT: Lead } \\
\text { IPSCs, VU, ECT, DOE: Contributor }\end{array}$ \\
\hline FY12 & On-going & $\begin{array}{l}\text { Facilitate exchange of validation } \\
\text { data }\end{array}$ & $\begin{array}{l}\text { IPSCs: Lead } \\
\text { CT, DOE: Assist with “business” issues }\end{array}$ \\
\hline
\end{tabular}


A Roadmap for NEAMS Capability Transfer

\begin{tabular}{|l|l|l|l|}
\hline Starting & Frequency & Activity & Roles \\
\hline FY13 & On-going & Execute NRC engagement strategy & TBD \\
\hline FY13 & On-going & Execute software distribution plan & TBD \\
\hline FY13* & On-going* & User support & $\begin{array}{l}\text { CT: Provide tier-1 user support } \\
\text { IPSCs: Provide tier-2 user support }\end{array}$ \\
\hline FY13* & On-going* & $\begin{array}{l}\text { Software documentation and tutorial } \\
\text { materials }\end{array}$ & $\begin{array}{l}\text { IPSCs: Lead, primary content provider } \\
\text { CT: Coordination, consistency, } \\
\text { refinement }\end{array}$ \\
\hline FY14* & On-going* & Live trainings & $\begin{array}{l}\text { IPSCs: Lead } \\
\text { CT: Assist }\end{array}$ \\
\hline $\begin{array}{l}\text { As } \\
\text { Needed }\end{array}$ & On-going & External developer support & $\begin{array}{l}\text { IPSCs: Lead } \\
\text { CT, ECT: Assist }\end{array}$ \\
\hline
\end{tabular}

* These activities can be implemented in a staged fashion, based on the different IPSCs, codes/capabilities, and level of sophistication/depth/detail. 


\title{
Appendix A Workshop Agenda
}

\section{Monday 4 April 2011 (Day 1)}

\author{
Time \\ Topic \\ Speaker/Discussion Leader \\ 8:30-9:00am \\ Working breakfast, discussions of recent events in the nuclear industry \\ 9:00-9:10am Welcome \\ Jim Peltz, DOE \\ and David Bernholdt, ORNL \\ 9:10-9:20am Introductions \\ David Bernholdt, ORNL \\ Introduction to the NEAMS Program \\ 9:20-9:40am \\ Overview of the NEAMS Program \\ Jim Peltz, DOE \\ 9:40-10:00am \\ NEAMS Fuels IPSC \\ Steve Hayes, INL \\ 10:00-10:20am NEAMS Reactors IPSC \\ David Pointer, ANL \\ 10:20-10:40am Break \\ 10:40-11:00am NEAMS Safeguards and Separations IPSC \\ David DePaoli, ORNL \\ 11:00-11:200am NEAMS Waste IPSC \\ Carter Edwards, SNL \\ 11:20-11:40am NEAMS Fundamental Methods and Models \\ Xin Sun, PNNL \\ User Outreach and Technology Transfer in Other Modeling \& Simulation Programs \\ 11:40-12:00pm Advanced Simulation and Computing (DOE NNSA) Gil Weigand, ORNL \\ 12:00-1:30pm Lunch (on your own) \\ 1:30-1:50pm SCALE Brad Rearden, ORNL \\ 1:50-2:10pm Consortium for Advanced Simulation of Light Water Jess Gehin, ORNL \\ Reactors (CASL) \\ 2:10-2:15pm Charge to Breakout Sessions David Bernholdt, ORNL \\ In-Depth Discussions of Capability Transfer Needs and Approaches \\ 2:15-3:30pm \\ Fuels and Reactors (Room 12) \\ Jess Gehin, ORNL \& Gil \\ Weigand, ORNL \\ Safeguards \& Separations and Waste (Room 13) \\ Jay Billings, ORNL \& Brad \\ Rearden, ORNL \\ 3:30-3:50pm Break \\ 3:50-5:00pm Fuels and Reactors (continued) \\ Safeguards \& Separations and Waste (continued) \\ 5:00pm Adjourn general session \\ 5:00-5:30pm Private briefing by AREVA team to DOE \& Lab Paul Murray, AREVA \\ participants \\ 5:30-6:00pm Private briefing by Enercon team to DOE \& Lab Steve Clark, Enercon \\ participants
}




\section{Tuesday 5 April 2011 (Day 2)}

Time

8:30-9:00am

9:15-9:30am

9:30-10:20am

10:20-10:40am

10:40-11:30am

11:30am-

12:00pm

12:00pm

12:00-1:30pm

1:30-3:30pm

Initial Reactions to What We Heard

Analysis of Common and Distinctive CT Needs

Across the IPSCs

3:30-3:50pm Break

3:50-5:00pm

Discussion of Roles for IPSCs and CT

Initial Sketch of the Roadmap

5:00pm Adjourn

Fuels and Reactors Breakout Summary Summary

Break

(continued) Leaders only.)

\section{Speaker/Discussion Leader}

Working breakfast, discussions of yesterday's sessions

Breakout Session Summaries and Full-Group Discussions

Jess Gehin, ORNL \& Gil Weigand, ORNL

Safeguards \& Separations and Waste Breakout Jay Billings, ORNL \& Brad Rearden, ORNL

David Bernholdt, ORNL

Adjourn general session (Remainder of meeting for NEAMS Participants and Breakout

Post-Mortem Analysis and Programmatic Discussions

(NEAMS Participants and Breakout Leaders Only)

David Bernholdt, ORNL

David Bernholdt, ORNL

David Bernholdt, ORNL 


\section{Appendix B Workshop Attendees}

Bernholdt, David

Berry, Dick

Billings, Jay Jay

Bowman, Steve

Bradley, Keith

Cipiti, Ben

Clark, Steve

de Almeida, Valmor

DePaoli, David

Edwards, Carter

Fanning, Tom

Gehin, Jess

Hayes, Steve

Hess, Charles

Hittner, Dominique

Khaleel, Mohammed

McCaskey, Alex

Murray, Paul

Peltz, James

Pereira, Candido

Phillips, Chris

Pointer, David

Rearden, Brad

Smith, Michael A.

Summers, Randy

Sun, Xin

Wang, Yifeng

Weigand, Gil

Wells, Alan

Worrall, Andrew
Oak Ridge National Laboratory

Shaw Group

Oak Ridge National Laboratory

Oak Ridge National Laboratory

Argonne National Laboratory

Sandia National Laboratories

Enercon Services Inc.

Oak Ridge National Laboratory

Oak Ridge National Laboratory

Sandia National Laboratories

Argonne National Laboratory

Oak Ridge National Laboratory

Idaho National Laboratory

Shaw Group

AREVA

Pacific Northwest National Laboratory

Oak Ridge National Laboratory

AREVA

Office of Nuclear Energy

Argonne National Laboratory

Energy Solutions

Argonne National Laboratory

Oak Ridge National Laboratory

Argonne National Laboratory

Sandia National Laboratories

Pacific Northwest National Laboratory

Sandia National Laboratories

Oak Ridge National Laboratory

NISYS Corporation/Enercon

UK National Nuclear Laboratory 